\title{
Gastric lesions in patients with Crohn's disease in Korea: a multicenter study
}

Hoonsub So ${ }^{1}$, Byong Duk Ye ${ }^{1,2}$, Young Soo Park ${ }^{3}$, Jihun Kim³ ${ }^{3}$ Joo Sung Kim ${ }^{4}$, Won Moon ${ }^{5}$, Kang-Moon Lee ${ }^{6}$, You Sun Kim ${ }^{7}$, Bora Keum ${ }^{8}$, Seong-Eun Kim ${ }^{9}$, Kyeong Ok Kim ${ }^{10}$, Eun Soo Kim ${ }^{11}$, Chang Kyun Lee ${ }^{12}$, Sung Pil Hong ${ }^{13}$, Jong Pil Im ${ }^{4}$, Ja Seol Koo ${ }^{14}$, Chang Hwan Choi ${ }^{15}$, Jeong Eun Shin ${ }^{16}$, Bo In Lee ${ }^{17}$, Kyu Chan Huh ${ }^{18}$, Young-Ho Kim ${ }^{19}$, Hyun-Soo Kim ${ }^{20}$, Young Sook Park ${ }^{21}$, Dong Soo Han ${ }^{22}$; Korean Association for the Study of Intestinal Diseases

${ }^{1}$ Department of Gastroenterology, ${ }^{2}$ Inflammatory Bowel Disease Center, ${ }^{3}$ Department of Pathology, University of Ulsan College of Medicine, Asan Medical Center, Seoul, ${ }^{4}$ Department of Internal Medicine, Seoul National University College of Medicine, Seoul, ${ }^{5}$ Department of Internal Medicine, Kosin University College of Medicine, Busan, ${ }^{6}$ Department of Internal Medicine, The Catholic University of Korea, St. Vincent's Hospital, Suwon, ${ }^{7}$ Department of Internal Medicine, Inje University College of Medicine, Seoul Paik Hospital, Seoul, ${ }^{8}$ Department of Internal Medicine, Institute of Digestive Disease and Nutrition, Korea University College of Medicine, Seoul, ${ }^{9}$ Department of Internal Medicine, Ewha Womans University School of Medicine, Ewha Mokdong Hospital, Seoul, ${ }^{10}$ Department of Internal Medicine, Yeungnam University College of Medicine, Daegu, ${ }^{11}$ Department of Internal Medicine, Keimyung University School of Medicine, Daegu, ${ }^{12}$ Department of Internal Medicine, Kyung Hee University School of Medicine, Seoul, ${ }^{13}$ Department of Internal Medicine and Institute of Gastroenterology, Yonsei University College of Medicine, Seoul, ${ }^{14}$ Department of Internal Medicine, Korea University College of Medicine, Korea University Ansan Hospital, Ansan, ${ }^{15}$ Department of Internal Medicine, ChungAng University College of Medicine, Seoul, ${ }^{16}$ Department of Internal Medicine, Dankook University College of Medicine, Cheonan, ${ }^{17}$ Department of Internal Medicine, The Catholic University of Korea, Seoul St. Mary's Hospital, Seoul, ${ }^{18}$ Department of Internal Medicine, Konyang University College of Medicine, Daejeon, ${ }^{19}$ Department of Internal Medicine, Sungkyunkwan University School of Medicine, Seoul, ${ }^{20}$ Department of Internal Medicine, Chonnam National University Medical School, Gwangju, ${ }^{21}$ Department of Internal Medicine, Eulji University School of Medicine, Seoul, ${ }^{22}$ Department of Internal Medicine, Hanyang University College of Medicine, Hanyang University Guri Hospital, Guri, Korea

Background/Aims: Gastric pathology and Helicobacter pylori (H. pylori) infection among Asian patients with Crohn's disease (CD) are still unclear. We evaluated gastric histologic features and frequency of $H$. pylori infection in Korean patients with CD. Methods: Among 492 patients with CD receiving upper gastrointestinal (GI) endoscopic evaluation in 19 Korean hospitals, we evaluated the endoscopic findings and gastric histopathologic features of 47 patients for our study. Histopathologic classification was performed using gastric biopsy tissues, and $H$. pylori infection was determined using the rapid urease test and histology. Results: There were 36 men (76.6\%), and the median age of patients at the time of upper GI endoscopy was 23.8 years (range, 14.2-60.5). For CD phenotype, ileocolonic disease was observed in 38 patients (80.9\%), and non-stricturing, nonpenetrating disease in 31 patients (66.0\%). Twenty-eight patients (59.6\%) complained of upper GI symptoms. Erosive gastritis was the most common gross gastric feature (66.0\%). Histopathologically, H. pylori-negative chronic active gastritis $(38.3 \%)$ was the most frequent finding. H. pylori testing was positive in 11 patients $(23.4 \%)$, and gastric noncaseating granulomata were detected in 4 patients $(8.5 \%)$. Gastric noncaseating granuloma showed a statistically significant association with perianal abscess/ fistula $(P=0.0496)$. Conclusions: $H$. pylori-negative chronic active gastritis appears to be frequent among Korean patients with $\mathrm{CD}$. The frequency of $H$. pylori infection was comparable with previous studies. An association with perianal complications suggests a prognostic value for gastric noncaseating granuloma in patients with CD. (Intest Res 2016;14:60-68)

Key Words: Crohn disease; Stomach; Helicobacter pylori; Gastritis; Granuloma 


\section{INTRODUCTION}

Crohn's disease (CD) is a chronic IBD of unknown etiology that can involve any site of the gastrointestinal (GI) tract, from the mouth to the anus. Symptomatic gastroduodenal involvement in CD is reported in $1 \%-5 \%$ according to Western literatures. ${ }^{1}$ However, in contrast to the low frequency of symptomatic gastroduodenal CD, routine upper GI endoscopy identifies microscopic inflammation in up to $70 \%$ of Western patients. ${ }^{2,3}$ Helicobacter pylori-negative gastritis has been reported in $10 \%-60 \%$ of patients with $\mathrm{CD} .^{4-6}$ Low infection rates of $H$. pylori in IBD patients compared with controls have been reported in Western literatures. ${ }^{7-17}$

Historically, IBD and CD have been regarded as rare among Asian people. However, in the past few decades, the incidence of IBD, including CD, is steadily increasing in Asia. ${ }^{18-21}$ The incidence of $\mathrm{CD}$ appears to be rising more rapidly than that of UC. ${ }^{19}$ Therefore, more attention is needed regarding the clinical characteristics of IBD, especially CD in Asian people. There are several differences in the clinical features and prognosis of CD in Asians compared with Western populations, such as male predominance, lower frequencies of isolated colonic disease, and probably a more favorable prognosis. ${ }^{19,20,22}$ Moreover, genetic backgrounds of Asian IBD patients also were reported to be different from those of Western patients. ${ }^{23}$ Clinical and genetic differences between Asian and Western patients with CD suggests the possibility of differences in upper GI lesions as well. However, this issue has not been properly investigated in an Asian population. Therefore, in this study, we aimed to characterize gastric lesions in Korean patients with CD in a multicenter study design.

\section{METHODS}

\section{Subjects}

Medical information of 492 patients with CD who underwent upper GI endoscopy in 19 Korean medical institutions was collected for this study. CD was diagnosed based on conventional clinical, radiologic, endoscopic, and histopathologic criteria. ${ }^{19,24}$ Among 492 subjects, 47 patients who met all of the following criteria were finally enrolled: (1) Patients who underwent biopsy for abnormal gastric lesions and/ or normal-looking gastric mucosa, and (2) Patients who received rapid urease test (RUT) from both the gastric antrum and corpus. We retrospectively reviewed the patients' medical records, upper GI endoscopic images and histopatholo- gy. The following demographic and clinical information was gathered: sex, date of CD diagnosis, date of upper GI endoscopy, presence of upper GI symptoms (epigastric soreness/ pain, nausea/vomiting, indigestion, and reflux), perianal abscess/fistula, ileocolonic noncaseating granuloma, medication for CD ever used (5-aminosalicylic acids, thiopurines, and anti-tumor necrosis factor agents), and CRP at the time of upper GI endoscopy. Location and behavior of CD were evaluated using the Montreal classification, excluding upper GI involvement (L4) and perianal disease modifier (p) ${ }^{25} \mathrm{CD}$ activity was evaluated with the CDAI, and was classified as remission (CDAI <150), mild activity (CDAI 150-219), moderate activity (CDAI 220-450), and severe activity (CDAI $>450){ }_{.}^{26,27}$ The study protocol was approved by the Institutional Review Boards of participating institutions.

\section{Upper GI Endoscopy, Histologic Evaluation, and H. pylori Infection Assessment}

All upper GI endoscopic evaluations were performed by expert GI endoscopists of the participating institutions. Gross mucosal findings by endoscopy were classified as described previously. ${ }^{28}$ Biopsies were obtained for pathologic evaluation from abnormal gastric lesions and/or normallooking gastric mucosa at the endoscopists' discretion. Additional biopsies were performed at both the gastric antrum and corpus for RUT. Serologic tests, urea breath test, and culture assay were not used to evaluate $H$. pylori infection. Histologic features were classified as described previously. ${ }^{5}$ Briefly, subjects were classified into one of the following categories: (1) H. pylori-negative chronic active gastritis, (2) H. pylori-negative chronic inactive gastritis, (3) H. pylori gastritis, (4) focally enhanced gastritis, and (5) normal. ${ }^{5} \mathrm{Be}-$ cause these histologic diagnoses are not mutually exclusive, the study subjects were classified into category of the most dominant feature. The presence of noncaseating granuloma was also added for groups 1-4 when present. For histopathologic diagnosis of gastric biopsies, electronic files of standard pathologic images for each category were distributed to participating researchers. Standard H\&E were performed for biopsy specimens. H. pylori was determined to be positive when RUT and/or histologic evaluation was positive.

\section{Statistical Analysis}

Continuous variables were expressed as the median with ranges. Discrete data were expressed as numbers and percentages. Study subjects' demographic and clinical charac- 
teristics were compared with regard to $H$. pylori-positivity and the presence of noncaseating granuloma. For comparative analyses, the Mann-Whitney $U$ test was used for continuous variables, and the chi-squared test or the Fisher's exact test was used for categorical variables, where appropriate. All statistical analysis and calculations were carried out using IBM SPSS Statistics for Windows (version 21.0; IBM Corp., Armonk, USA). A $P<0.05$ was considered statistically significant.

\section{RESULTS}

\section{Demographic and Disease Characteristics}

Among 492 subjects, a total of 47 patients meeting all of the selection criteria were enrolled. These patients had been diagnosed with CD between June 1998 and October 2011. There were 36 men (76.6\%), and the median age at diagnosis of CD was 23.1 years (range, 12.0-49.9). Upper GI endoscopies were performed between September 2002 and February 2013. At the time of upper GI endoscopy, the median age of the patients was 23.8 years (range, 14.2-60.5) and the median interval from diagnosis of CD to upper GI endoscopy was 1.6 months (range, $0-168.3$ ).

At the time of upper GI endoscopy, ileocolonic location (80.9\%), and non-stricturing, non-penetrating behavior (66.0\%) were the dominant phenotypes. Active and/or past perianal abscess/fistula was identified in 23 patients (48.9\%). Moderate activity (42.6\%) by CDAI was the most common disease activity at upper GI endoscopy. In 22 patients (46.8\%), noncaseating granuloma had previously been identified from ileocolonoscopic biopsy specimens. Twenty-eight patients (59.6\%) complained of upper GI symptoms. CD medications given in the past to patients included 5-aminosalicylic acids (21 patients, $44.7 \%$ ), thiopurines (11 patients, $23.4 \%$ ), and anti-tumor necrosis factor agents (2 patients, $4.3 \%)$. In 39 patients (83.0\%), CRP was checked at the time of upper GI endoscopy, and the median level was $2.54 \mathrm{mg} / \mathrm{dL}$ (range, 0.10-11.18). The characteristics of study subjects are summarized in Table 1.

\section{Upper GI Endoscopic and Pathologic Findings}

Erosive gastritis was most common $(\mathrm{n}=31,66.0 \%)$ feature found on upper endoscopy, followed by normal findings $(\mathrm{n}=7,14.9 \%)$. H. pylori testing was positive in 11 patients (23.4\%). H. pylori-negative chronic active gastritis was most common histopathologic feature $(\mathrm{n}=18,38.3 \%)$. Noncaseat- ing granuloma was detected in 4 patients (8.5\%). The upper GI endoscopic and pathologic findings of study subjects are summarized in Table 2. Representative images of upper GI endoscopy and pathologic features of $H$. pylori-negative chronic active gastritis with noncaseating granuloma are presented in Fig. 1 and Fig. 2, respectively.

When the association between $H$. pylori-positivity and various clinical, laboratory, and histologic characteristics was analyzed, there were no variables showing an association with $H$. pylori-positivity (Table 3 ). The association between gastric noncaseating granuloma and clinical, laboratory, and histologic characteristics was also analyzed, and gastric noncaseating granuloma was significantly associated with perianal abscess/fistula $(P=0.0496$, Table 4$)$.

Table 1. Baseline Characteristics of Subjects

\begin{tabular}{lc}
\multicolumn{1}{c}{ Characteristic } & $\mathbf{n = 4 7}$ \\
\hline Male & $36(76.6)$ \\
Age at diagnosis of CD (yr) & $23.1(12.0-49.9)$ \\
Age at the time of upper Gl endoscopy (yr) & $23.8(14.2-60.5)$ \\
Interval from CD diagnosis to upper & $1.6(0-168.3)$ \\
Gl endoscopy (mo) & \\
Montreal disease location & \\
lleum & $4(8.5)$ \\
Colon & $5(10.6)$ \\
lleocolon & $38(80.9)$ \\
Montreal disease behavior & \\
Non-stricturing, non-penetrating & $31(66.0)$ \\
Stricturing & $7(14.9)$ \\
Penetrating & $9(19.1)$ \\
CDAl & \\
Remission & $19(40.4)$ \\
Mild & $7(14.9)$ \\
Moderate & $20(42.6)$ \\
Missing & $1(2.1)$ \\
Presence of upper Gl symptoms & $28(59.6)$ \\
5-ASA and/or current medication for CD & \\
Thiopurines & $21(44.7)$ \\
\hline & \\
\hline & \\
Anti-TNF agents & \\
\hline
\end{tabular}

Values are presented as median (range) or $n(\%)$.

GI, gastrointestinal; 5-ASA, 5-aminosalicylic acid; TNF, tumor necrosis factor. 
Table 2. Endoscopic and Histologic Findings of Subjects $(n=47)$

\begin{tabular}{|c|c|c|c|c|}
\hline \multirow[b]{2}{*}{ Endoscopic findings } & \multicolumn{4}{|c|}{ Histologic findings } \\
\hline & $\begin{array}{l}\text { HP-negative chronic } \\
\text { active gastritis }(n=18)\end{array}$ & $\begin{array}{c}\text { HP-negative chronic } \\
\text { inactive gastritis }(n=13)\end{array}$ & $\begin{array}{l}\text { HP gastritis } \\
(n=11)\end{array}$ & $\begin{array}{r}\text { Norma } \\
(n=5)\end{array}$ \\
\hline$E G(n=28)$ & $14^{\mathrm{a}}$ & 7 & 7 & \\
\hline Normal $(n=7)$ & & & 2 & 5 \\
\hline $\operatorname{BGU}(n=6)$ & $3^{b}$ & 1 & 2 & \\
\hline$E G+C S G(n=3)$ & 1 & $2^{c}$ & & \\
\hline $\operatorname{CSG}(n=3)$ & & 3 & & \\
\hline
\end{tabular}

${ }^{a}$ One patient was found to have noncaseating granuloma.

${ }^{b}$ One patient was found to have noncaseating granuloma, another was found to have combined atrophic change with noncaseating granuloma, and the remaining patient was found to have combined gastric fistula and noncaseating granuloma.

'One patient was found to have noncaseating granuloma.

$\mathrm{HP}$, Helicobacter pylori; EG, Erosive gastritis; BGU, Benign gastric ulcer; CSG, Chronic superficial gastritis.
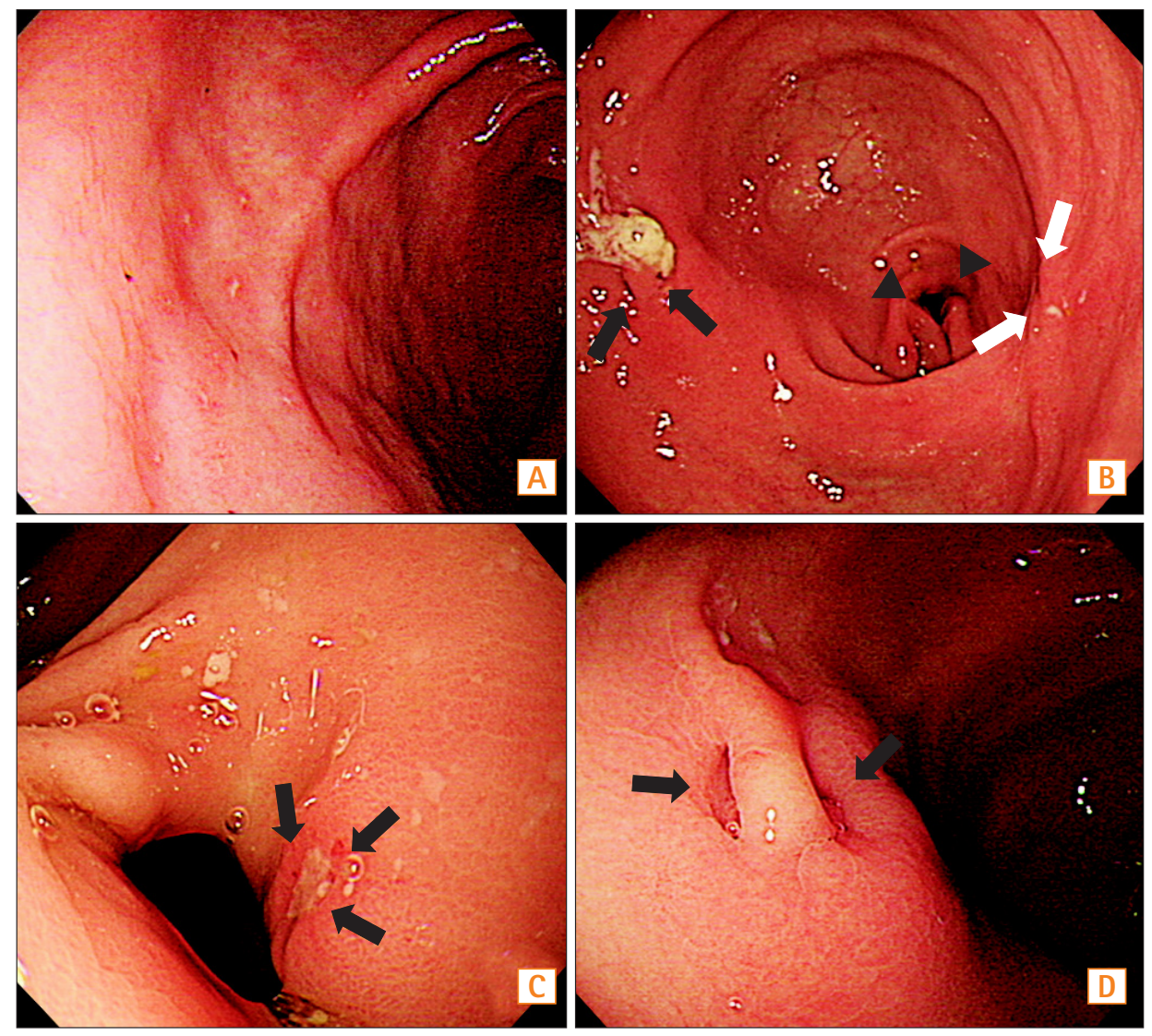

Fig. 1. Representative upper gastrointestinal endoscopic images of study subjects (A: patient 1, B-D: patient 2). (A) Multiple aphthous erosions are observed in the anterior wall of the gastric antrum. (B) The opening of a fistula in the anterior wall of the antrum (black arrows) and deformity of the pyloric ring due to active ulcer (arrowheads) are observed. On the posterior wall of the antrum, an ulcer scar is also observed (white arrows). (C) Closer view of ulcer of the pyloric ring (arrows) (D) Closer view of the opening of the fistula (arrows). A fistulous tract between the small bowel and gastric antrum was found at surgery.

\section{DISCUSSION}

In this pilot study, we identified $H$. pylori-negative chronic active gastritis in nearly $40 \%$, and $H$. pylori gastritis in nearly $25 \%$, of Korean patients with CD. Gastric noncaseating granuloma was observed in $8.5 \%$ of study subjects and was significantly associated with perianal abscess/fistula.
According to European evidence-based consensus on the diagnosis and management of $\mathrm{CD}$, at the time of $\mathrm{CD}$ diagnosis, further investigation to examine the location and extent of disease in the upper GI tract or small bowel is recommended, regardless of the findings at ileocolonoscopy. ${ }^{29}$ Moreover, in cases of IBD unclassified, upper GI endoscopy could be more useful than imaging studies for establishing 

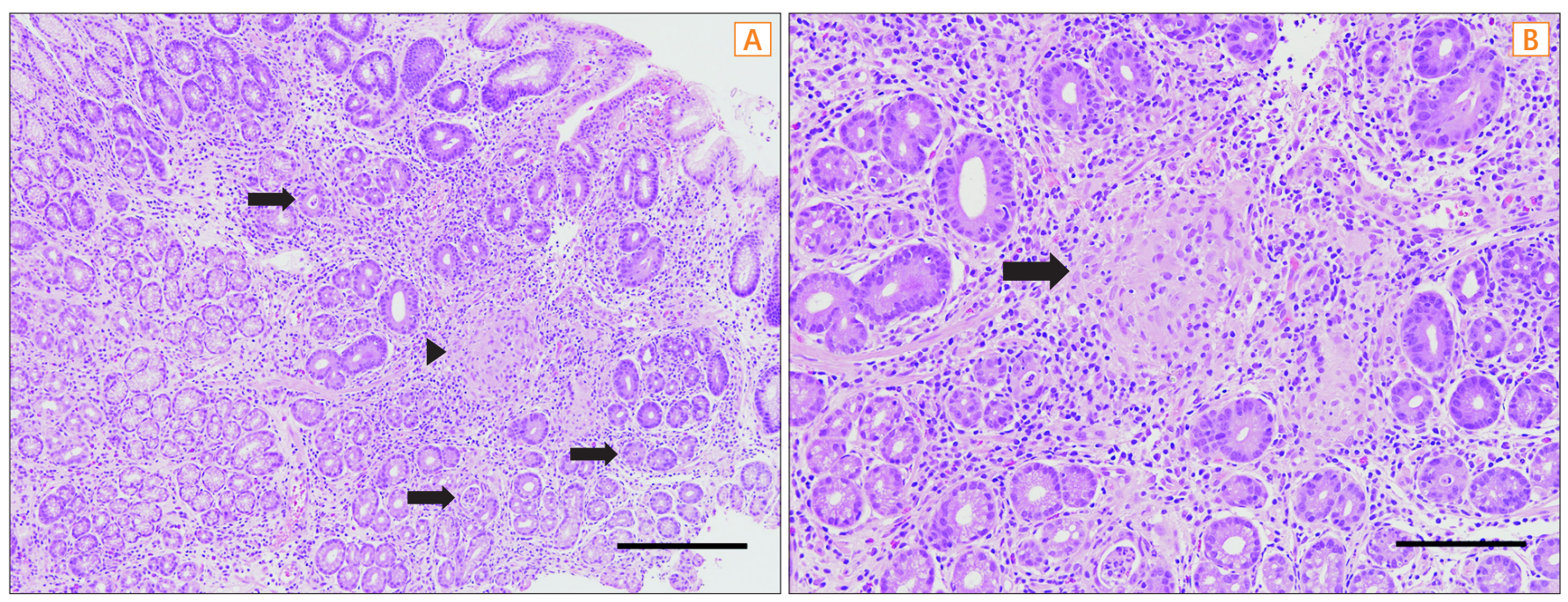

Fig. 2. Histology of biopsy specimens from antral erosions of patient 1. (A) The gastric mucosa showing multifocal aggregates of mixed inflammatory cells in the lamina propria, with multiple crypt abscesses (arrows) and a focal noncaseating granuloma (arrowhead) (HEE, $\times 100 ; s c a l e ~ b a r=300 \mu m)$. (B) The granuloma is of medium size and has no necrosis (arrow) (H\&E, x200; scale bar=120 $\mu \mathrm{m}$ ).

Table 3. Association of Helicobacter pylori-positivity With Various Clinical, Laboratory, and Histologic Characteristics

\begin{tabular}{|c|c|c|c|}
\hline Variable & HP-positive $(n=11)$ & HP-negative $(n=36)$ & $P$-value \\
\hline Male & $6(54.5)$ & $30(83.3)$ & $0.0973^{\mathrm{a}}$ \\
\hline Age at $C D$ diagnosis & $19.1(14.0-39.0)$ & $23.5(12.0-49.9)$ & $0.2855^{b}$ \\
\hline Age at upper Gl endoscopy & $19.4(14.2-42.9)$ & $26.9(16.0-60.5)$ & $0.3857^{\circ}$ \\
\hline Montreal disease location & & & $0.2784^{c}$ \\
\hline lleum & $0(0)$ & $4(11.1)$ & \\
\hline Colon & $0(0)$ & $5(13.9)$ & \\
\hline Ileocolon & $11(100)$ & $27(75.0)$ & \\
\hline Montreal disease behavior & & & $0.1532^{\mathrm{a}}$ \\
\hline Non-stricturing, non-penetrating & $10(90.9)$ & $21(58.3)$ & \\
\hline Stricturing & $0(0)$ & $7(19.5)$ & \\
\hline Penetrating & $1(9.1)$ & $8(22.2)$ & \\
\hline Perianal abscess/fistula & $5(45.5)$ & $18(50.0)$ & $0.7918^{c}$ \\
\hline CDAl & & & $0.1877^{\mathrm{a}}$ \\
\hline Remission & $2(18.2)$ & $17(47.2)$ & \\
\hline Mild & $1(9.1)$ & $6(16.7)$ & \\
\hline Moderate & $7(63.6)$ & $13(36.1)$ & \\
\hline Missing & $1(9.1)$ & $0(0)$ & \\
\hline $\mathrm{CRP}(\mathrm{mg} / \mathrm{dL})$ & $2.54(0.67-10.50)(n=8)$ & $2.80(0.10-11.18)(n=31)$ & $0.6764^{b}$ \\
\hline Ileocolonic noncaseating granuloma & $7(63.6)$ & $15(41.7)$ & $0.2012^{c}$ \\
\hline Gastric noncaseating granuloma & $0(0)$ & $4(11.1)$ & $0.5597^{\mathrm{a}}$ \\
\hline
\end{tabular}

Values are presented as median (range) or $n(\%)$.

${ }^{a}$ Fisher's exact test.

${ }^{b} M a n n-W h i t n e y U$ test.

'Chi-squared test.

HP, Helicobacter pylori; GI, gastrointestinal; CDAl, Crohn's disease activity index. 
Table 4. Association of Gastric Noncaseating Granuloma With Various Clinical, Laboratory, and Histologic Characteristics

\begin{tabular}{|c|c|c|c|}
\hline Variable & $\begin{array}{l}\text { Noncaseating granuloma-positive } \\
\qquad(\mathrm{n}=4)\end{array}$ & $\begin{array}{l}\text { Noncaseating granuloma-negative } \\
\qquad(\mathrm{n}=43)\end{array}$ & $P$-value \\
\hline Male & $4(100)$ & $32(74.4)$ & $0.5597^{\circ}$ \\
\hline Age at $C D$ diagnosis & $22.0(17.0-37.2)$ & $23.1(12.0-49.9)$ & $0.7522^{b}$ \\
\hline Age at upper Gl endoscopy & $31.2(18.0-37.2)$ & $23.2(14.2-60.5)$ & $0.7527^{\mathrm{b}}$ \\
\hline Montreal disease location & & & $0.5862^{a}$ \\
\hline lleum & $0(0)$ & $4(9.3)$ & \\
\hline Colon & $1(25.0)$ & $4(9.3)$ & \\
\hline Ileocolon & $3(75.0)$ & $35(81.4)$ & \\
\hline Montreal disease behavior & & & $0.4204^{a}$ \\
\hline Non-stricturing, non-penetrating & $2(50.0)$ & $29(67.4)$ & \\
\hline Stricturing & $1(25.0)$ & $6(14.0)$ & \\
\hline Penetrating & $1(25.0)$ & $8(18.6)$ & \\
\hline Perianal abscess/fistula & $4(100)$ & $19(44.2)$ & $0.0496^{a}$ \\
\hline CDAl & & & $0.2478^{a}$ \\
\hline Remission & $1(25.0)$ & $18(41.9)$ & \\
\hline Mild & $2(50.0)$ & $5(11.6)$ & \\
\hline Moderate & $1(25.0)$ & $19(44.2)$ & \\
\hline Missing & $0(0)$ & $1(2.3)$ & \\
\hline $\mathrm{CRP}(\mathrm{mg} / \mathrm{dL})$ & $1.83(0.18-5.40)$ & $2.56(0.10-11.18)(n=35)$ & $0.5473^{b}$ \\
\hline Ileocolonic noncaseating granuloma & $3(75.0)$ & $19(44.2)$ & $0.3278^{\mathrm{a}}$ \\
\hline
\end{tabular}

Values are presented as median (range) or $\mathrm{n}(\%)$.

${ }^{a}$ Fisher's exact test.

${ }^{b}$ Mann-Whitney $U$ test.

GI, gastrointestinal; CDAl, Crohn's disease activity index.

the diagnosis of $\mathrm{CD}$, since endoscopic biopsy can document the presence of granulomata or focally-enhanced or focal active gastritis. ${ }^{29}$

H. pylori-negative chronic active gastritis has been reported to be more common in patients with CD than in the general population. In a recent study with endoscopic biopsy specimens, $H$. pylori-negative chronic active gastritis was diagnosed in $16.8 \%$ of $\mathrm{CD}$ patients (35/208), and $1.6 \%$ of controls (80/4942), making the diagnosis significantly more frequent in patients with CD (OR, 11.7; 95\% CI, 7.5-18.0) than in controls. ${ }^{5}$ Moreover, among those 21 years of age or younger, $H$. pylori-negative chronic active gastritis was detected in $26.2 \%$ of CD patients (39/149), yielding an OR of 15.1 (95\% CI, 9.8-22.9). ${ }^{6}$ In our study, H. pylori-negative chronic active gastritis was diagnosed in $38.3 \%$ of study subjects, which is slightly higher than the frequency reported in recent Western studies. ${ }^{5,6}$ This finding needs to be confirmed in a larger-scaled study with controls, evaluated together with the clinical implications of gastric pathologic features, such as an association with prognosis.

Recent laboratory evidence illustrates that $H$. pylori plays a certain role in regulation of the immune system. ${ }^{30} \mathrm{~A}$ possible causative role of $H$. pylori in the development of autoimmune diseases such as immune thrombocytopenia, and a possible protective role of $H$. pylori against asthma also suggest interplay between $H$. pylori and the human immune system. ${ }^{30-32}$ From the epidemiologic point of view, the higher prevalence of IBD in areas with lower rates of $H$. pylori infection and the rising incidence of IBD together with increased use of eradication therapy in $H$. pylori endemic areas suggests an association between $H$. pylori infection and IBD. ${ }^{20,33}$ Several previous Western studies reported low rate of $H$. pylori infection in patients with IBD as assessed through serologic evaluation, ${ }^{7,9,11,13-15}$ or histology and/or RUT., ${ }^{8,10,17}$ A Japanese study reported $36 \% \mathrm{H}$. pylori-positivity by serologic and histologic evaluation among patients with 
CD (9/25), and a lower H. pylori infection rate among patients with IBD compared with controls ( $29.4 \%$ vs. $52.0 \%$; RR, 0.57; 95\% CI, 0.32-1.00). ${ }^{34}$ Combining multiple studies from Europe, North America, South America, and Japan, a recent meta-analysis reported the lower overall rate of $H$. pylori infection in patients with IBD compared with controls $(27.1 \%$ vs. 40.9\%; RR, 0.64; 95\% CI, 0.54-0.75). ${ }^{33}$ A previous Korean multicenter study also compared the prevalence of $H$. pylori infection using urea breath test in 169 patients with UC, 147 with $\mathrm{CD}$, and 316 age- and sex-matched healthy controls. ${ }^{35}$ They found significantly lower rates of $H$. pylori infection in both CD (17.7\%) and UC patients (32.0\%) than in controls (52.5\%) (CD vs. controls, $P<0.001$ and UC vs. controls, $P<0.001) .{ }^{35} H$. pylori-positivity in our study was $23.4 \%$, which is in between the rates reported in a Korean study ${ }^{35}$ and a Japanese study. ${ }^{34}$ However, caution is needed in interpreting and comparing study results, due to differences in the diagnostic methods, study population, and study period.

There have been several studies on the association of noncaseating granuloma with disease severity and clinical outcome of patients with CD. Granulomata observed in the resected intestinal specimens were associated with post-operative endoscopic recurrence and reoperation in patients with $\mathrm{CD}^{36-38}$ In addition, the presence of granulomata within small bowel or colonic surgical specimens of patients with CD was associated with perianal fistula. ${ }^{39}$ Similarly, epithelioid granulomata noted in endoscopic rectosigmoid biopsies obtained from untreated pediatric patients at initial presentation of CD showed associations with more extensive disease involvement, perianal disease, and increased need for surgery during follow-up, suggesting a worse prognosis. ${ }^{40}$ In line with those reports, among children, granulomata detected in the GI tract at diagnosis of CD were associated with perianal disease and infliximab treatment during follow-up. ${ }^{41}$ In our study, noncaseating gastric granulomata were observed in $8.5 \%$ of study subjects, which is within the reported frequency of 5\%-83\% from gastric biopsies in $\mathrm{CD}^{42-44}$ The suggested association between gastric noncaseating granuloma and perianal abscess/fistula from our study needs further confirmation with larger number of cases, including an assessment of the association with other clinical outcomes.

The limitations of our study include its retrospective design, referral center-based study population, and small number of patients. In addition, control subjects without evidence of CD were not investigated for comparison. To evaluate H. pylori, histologic evaluation using special staining such modified Giemsa staining, urea breath test, and serology were not performed. In addition, previous use of an- tibiotics and proton pump inhibitors at the time of $\mathrm{H}$. pylori evaluation was not properly investigated. However, to avoid possible bias, a standard protocol for evaluating and classifying pathologic features were provided to all participating institutions, and the enrolled cases were selected by a single IBD specialist after thorough evaluation of data. In addition, as far as we are aware, this is the first multicenter study to evaluate both gross and microscopic gastric lesions of Asian patients with CD.

In conclusion, $H$. pylori-negative chronic active gastritis appears to be common in Korean patients with CD, similar to the frequency seen in Western patients. The H. pylori infection rate was comparable with previous studies. Gastric noncaseating granuloma was associated with perianal abscess/fistula, suggesting an association of granuloma with poor prognosis. A further well-designed prospective study is needed to elucidate the upper GI characteristics of Korean and Asian patients with CD.

\section{REFERENCES}

1. Turner D, Griffiths AM. Esophageal, gastric, and duodenal manifestations of IBD and the role of upper endoscopy in IBD diagnosis. Curr Gastroenterol Rep 2009;11:234-237.

2. Korelitz BI, Waye JD, Kreuning J, et al. Crohn's disease in endoscopic biopsies of the gastric antrum and duodenum. Am J Gastroenterol 1981;76:103-109.

3. Cameron DJ. Upper and lower gastrointestinal endoscopy in children and adolescents with Crohn's disease: a prospective study. J Gastroenterol Hepatol 1991;6:355-358.

4. Halme L, Kärkkäinen P, Rautelin H, Kosunen TU, Sipponen P. High frequency of helicobacter negative gastritis in patients with Crohn's disease. Gut 1996;38:379-383.

5. Sonnenberg A, Melton SD, Genta RM. Frequent occurrence of gastritis and duodenitis in patients with inflammatory bowel disease. Inflamm Bowel Dis 2011;17:39-44.

6. Genta RM, Sonnenberg A. Non-Helicobacter pylori gastritis is common among paediatric patients with inflammatory bowel disease. Aliment Pharmacol Ther 2012;35:1310-1316.

7. el-Omar E, Penman I, Cruikshank G, et al. Low prevalence of Helicobacter pylori in inflammatory bowel disease: association with sulphasalazine. Gut 1994;35:1385-1388.

8. Mantzaris GJ, Archavlis E, Zografos C, Zavos K, Petraki K, Triadaphyllou G. Low prevalence of Helicobacter pylori in inflammatory bowel disease: association with sulfasalazine. Am J Gastroenterol 1995;90:1900. 
9. Wagtmans MJ, Witte AM, Taylor DR, et al. Low seroprevalence of Helicobacter pylori antibodies in historical sera of patients with Crohn's disease. Scand J Gastroenterol 1997;32:712-718.

10. Meining A, Bayerdörffer E, Bastlein E, et al. Focal inflammatory infiltrations in gastric biopsy specimens are suggestive of Crohn's disease. Crohn's Disease Study Group, Germany. Scand J Gastroenterol 1997;32:813-818.

11. Parente F, Molteni P, Bollani S, et al. Prevalence of Helicobacter pylori infection and related upper gastrointestinal lesions in patients with inflammatory bowel diseases. A cross-sectional study with matching. Scand J Gastroenterol 1997;32:1140-1146.

12. Parente F, Cucino C, Bollani S, et al. Focal gastric inflammatory infiltrates in inflammatory bowel diseases: prevalence, immunohistochemical characteristics, and diagnostic role. Am J Gastroenterol 2000;95:705-711.

13. Väre PO, Heikius B, Silvennoinen JA, et al. Seroprevalence of Helicobacter pylori infection in inflammatory bowel disease: is Helicobacter pylori infection a protective factor? Scand J Gastroenterol 2001;36:1295-1300.

14. Guslandi M, Fanti L, Testoni PA. Helicobacter pylori seroprevalence in Crohn's disease: lack of influence by pharmacological treatment. Hepatogastroenterology 2002;49:1296-1297.

15. Triantafillidis JK, Gikas A, Apostolidiss N, Merikas E, Mallass E, Peros G. The low prevalence of helicobacter infection in patients with inflammatory bowel disease could be attributed to previous antibiotic treatment. Am J Gastroenterol 2003;98:1213-1214.

16. Prónai L, Schandl L, Orosz Z, Magyar P, Tulassay Z. Lower prevalence of Helicobacter pylori infection in patients with inflammatory bowel disease but not with chronic obstructive pulmonary disease - antibiotic use in the history does not play a significant role. Helicobacter 2004;9:278-283.

17. Sładek M, Jedynak-Wasowicz U, Wedrychowicz A, KowalskaDuplaga K, Pieczarkowski S, Fyderek K. The low prevalence of Helicobacter pylori gastritis in newly diagnosed inflammatory bowel disease children and adolescent. Przegl Lek 2007;64(Suppl 3):65-67.

18. Yao T, Matsui T, Hiwatashi N. Crohn's disease in Japan: diagnostic criteria and epidemiology. Dis Colon Rectum 2000;43(Suppl 10):S85-S93.

19. Yang SK, Yun S, Kim JH, et al. Epidemiology of inflammatory bowel disease in the Songpa-Kangdong district, Seoul, Korea, 1986-2005: a KASID study. Inflamm Bowel Dis 2008;14:542549.

20. Thia KT, Loftus EV, Jr., Sandborn WJ, Yang SK. An update on the epidemiology of inflammatory bowel disease in Asia. Am J Gastroenterol 2008;103:3167-3182.
21. Chuang CH, Lin SH, Chen CY, Sheu BS, Kao AW, Wang JD. Increasing incidence and lifetime risk of inflammatory bowel disease in Taiwan: a nationwide study in a low-endemic area 1998-2010. Inflamm Bowel Dis 2013;19:2815-2819.

22. Park SH, Yang SK, Park SK, et al. Long-term prognosis of Crohn's disease and its temporal change between 1981 and 2012: a hospital-based cohort study from Korea. Inflamm Bowel Dis 2014;20:488-494.

23. Ng SC, Tsoi KK, Kamm MA, et al. Genetics of inflammatory bowel disease in Asia: systematic review and meta-analysis. Inflamm Bowel Dis 2012;18:1164-1176.

24. Loftus EV, Jr., Silverstein MD, Sandborn WJ, Tremaine WJ, Harmsen WS, Zinsmeister AR. Crohn's disease in Olmsted County, Minnesota, 1940-1993: incidence, prevalence, and survival. Gastroenterology 1998;114:1161-1168.

25. Satsangi J, Silverberg MS, Vermeire S, Colombel JF. The Montreal classification of inflammatory bowel disease: controversies, consensus, and implications. Gut 2006;55:749-753.

26. Best WR, Becktel JM, Singleton JW, Kern F, Jr. Development of a Crohn's disease activity index. National Cooperative Crohn's Disease Study. Gastroenterology 1976;70:439-444.

27. Sostegni R, Daperno M, Scaglione N, Lavagna A, Rocca R, Pera A. Review article: Crohn's disease: monitoring disease activity. Aliment Pharmacol Ther 2003;17(Suppl 2):11-17.

28. Park HK, Kim N, Lee SW, et al. The distribution of endoscopic gastritis in 25,536 heath check-up subjects in Korea. Korean J Helicobacter Up Gastrointest Res 2012;12:237-243.

29. Van Assche G, Dignass A, Panes J, et al. The second European evidence-based Consensus on the diagnosis and management of Crohn's disease: Definitions and diagnosis. J Crohns Colitis 2010;4:7-27.

30. Hasni SA. Role of Helicobacter pylori infection in autoimmune diseases. Curr Opin Rheumatol 2012;24:429-434.

31. Chen Y, Blaser MJ. Helicobacter pylori colonization is inversely associated with childhood asthma. J Infect Dis 2008;198:553560 .

32. Reibman J, Marmor M, Filner J, et al. Asthma is inversely associated with Helicobacter pylori status in an urban population. PLoS One 2008;3:e4060. doi: 10.1371/journal.pone.0004060.

33. Luther J, Dave M, Higgins PD, Kao JY. Association between Helicobacter pylori infection and inflammatory bowel disease: a meta-analysis and systematic review of the literature. Inflamm Bowel Dis 2010;16:1077-1084.

34. Furusu H, Murase K, Nishida Y, et al. Accumulation of mast cells and macrophages in focal active gastritis of patients with Crohn's disease. Hepatogastroenterology 2002;49:639-643. 
35. Song MJ, Park DI, Hwang SJ, et al. The Prevalence of Helicobacter pylori Infection in Korean Patients with Inflammatory Bowel Disease, a Multicenter Study. Korean J Gastroenterol 2009;53:341-347.

36. Yamamoto T. Prevention of recurrence after surgery for Crohn's disease: efficacy of infliximab. World J Gastroenterol 2010;16:5405-5410.

37. Simillis C, Jacovides M, Reese GE, Yamamoto T, Tekkis PP. Meta-analysis of the role of granulomas in the recurrence of Crohn disease. Dis Colon Rectum 2010;53:177-185.

38. Kotze PG, Saad-Hossne R. Biological therapy for the prevention and treatment of postoperative endoscopic recurrence in Crohn's disease: time for acceptance? Intest Res 2013;11:256260.

39. Denoya P, Canedo J, Berho M, et al. Granulomas in Crohn's disease: does progression through the bowel layers affect presentation or predict recurrence? Colorectal Dis 2011;13:1142-1147.
40. Markowitz J, Kahn E, Daum F. Prognostic significance of epithelioid granulomas found in rectosigmoid biopsies at the initial presentation of pediatric Crohn's disease. J Pediatr Gastroenterol Nutr 1989;9:182-186.

41. De Matos V, Russo PA, Cohen AB, Mamula P, Baldassano RN, Piccoli DA. Frequency and clinical correlations of granulomas in children with Crohn disease. J Pediatr Gastroenterol Nutr 2008;46:392-398.

42. Wagtmans MJ, van Hogezand RA, Griffioen G, Verspaget HW, Lamers CB. Crohn's disease of the upper gastrointestinal tract. Neth J Med 1997;50:S2-S7.

43. Loftus EV, Jr. Upper gastrointestinal tract Crohn's disease. Clin Perspect Gastroenterol 2002;5:188-191.

44. Kefalas CH. Gastroduodenal Crohn's disease. Proc (Bayl Univ Med Cent) 2003;16:147-151. 